\title{
Ignition behaviour of different rank coals in an entrained flow reactor
}

\author{
J. Faúndez ${ }^{2}$, A. Arenillas ${ }^{1}$, F. Rubiera ${ }^{1 *}$, X. García ${ }^{2}$, A.L. Gordon ${ }^{2}$, J.J. Pis ${ }^{1}$ \\ ${ }^{1}$ Instituto Nacional del Carbón (INCAR), CSIC. Apartado 73. 33080 Oviedo. Spain \\ ${ }^{2}$ Departamento de Ingeniería Química, Universidad de Concepción. P.O. Box 160-C.
} Concepción. Chile

\begin{abstract}
An experimental study to determine the temperature and mechanism of coal ignition was carried out by using an entrained flow reactor (EFR) at relatively high coal feed rates $\left(0.5 \mathrm{~g} \mathrm{~min}^{-1}\right)$. Seven coals ranging in rank from subbituminous to semianthracite, were tested and the evolved gases $\left(\mathrm{O}_{2}, \mathrm{CO}, \mathrm{CO}_{2}, \mathrm{NO}\right)$ were measured continuously. The ignition temperature was evaluated from the gas evolution profiles, and it was found to be inversely correlated to the reactivity of the coal, as reflected by the increasing values of the ignition temperature in the sequence: subbituminous, high volatile bituminous, low volatile bituminous and semianthracite coals. The mechanism of ignition varied from a heterogeneous mechanism for subbituminous, low volatile bituminous and semianthracite coals, to a homogeneous mechanism for high volatile bituminous coals. A thermogravimetric analyser (TGA) was also used to evaluate coal ignition behaviour. Both methods, TGA and EFR, were in agreement as regards the mechanism of coal ignition. From the SEM micrographs of the coal particles retrieved from the cyclone, it was possible to observe the external appearance of the particles before, during and after ignition. The micrographs confirmed the mechanism deduced from the gas profiles.
\end{abstract}

Keywords: Ignition; coal; entrained flow reactor; SEM 


\section{Introduction}

Ignition is the substantial burning of a combustible material. This requires that the loss of heat be balanced by the heat release at the ignition temperature [1,2]. The ignition of coal particles is an important preliminary step in the coal combustion process due to its influence on flame stability, the formation and emission of pollutants, and flame extinction. The reactivity and ignition behaviour of coal particles is of considerable importance for designing the boiler and controlling the combustion process. Coal particles can ignite either homogeneously, where the initial step is the pyrolysis and ignition of the volatiles followed by the ignition of the char, or heterogeneously, which involves the direct attack of oxygen on the whole sample particle $[3,4]$.

It has been established that neither temperature nor the mechanism of ignition are inherent properties of coal, and that they depend on the sample mass, the heating rate of the particle, the surrounding gas, and the ignition indicator [5]. In general, ignition depends on the type and reaction conditions of the test apparatus [6], and there is no widely accepted method for determining ignition temperatures. This is reflected by the diversity of experimental techniques that have been used to study coal particle ignition [2,5]. Thermogravimetric techniques (TGA/DTG) and drop tube furnaces are among the most common methods used to study coal ignition. Although TGA techniques have been widely employed to determine the ignition behaviour of coal [7-11] they operate at very different conditions to those encountered in a pulverised coal combustor. Thus, other bench equipment such as drop tube furnaces and entrained flow reactors, which simulate more closely the combustion conditions of industrial pf combustors (i.e., continuous coal feeding, particle residence time, heating rate), have been used [12-13]. There are, however, some shortcomings associated with the use of this equipment such as the use of sized fractions of coal or the operation under laminar flow conditions. 
Nevertheless, the pilot- and full-scale tests are costly to operate and the above techniques can help in the understanding of coal ignition behaviour.

In addition, different measurement techniques have been employed to determine the ignition temperature of pulverised coal. In this regard, some of the most common approaches used to estimate the temperature of ignition are based on the visual observation of the number of flashes emitted [14], detection of the light emissions with photomultipliers [15], measurement of the particle temperature by means of thermocouples [16], or following the evolution of the gaseous products during coal particle ignition and burnout $[17,18]$.

This work is concerned with determining the temperature and mechanism of ignition of different rank coals under conditions where particle interactions take place. To this end, a laminar entrained flow reactor, operating at high coal feed rates was used in order to promote interactive effects between the particles. Thus, group behaviour rather than single particle behaviour applies [19,20], and this is important for properly approximating the particle interactions that occur in industrial coal combustion and gasification processes. It should be noted that the ignition temperatures reported in this paper correspond to the gas temperature at which ignition takes place. In addition, due to the lack of a standardised methodology for determining coal ignition temperature and the wide variety of equipment and operating conditions used for its evaluation, the values should be regarded as trends rather than absolute values [5].

\section{Experimental}

An electrically heated, laminar entrained flow reactor with a reaction zone of $170 \mathrm{~cm}$ and an internal diameter of $4 \mathrm{~cm}$, capable of reaching a maximum temperature of 1100 ${ }^{\circ} \mathrm{C}$, was used for the ignition studies. Coal was entrained in the primary carrier gas, at 
ambient temperature, by a rotary feed system and introduced into the furnace through an air-cooled injection probe. The secondary gas was preheated before being introduced into the furnace through two concentric flow straighteners, located in the annular space between the injector and the furnace wall. The gas flow rates in the furnace were adjusted to ensure the specified gas residence time. A water-cooled collecting probe was inserted into the reaction chamber from below. The reaction products were quenched by supplying nitrogen. The char samples were removed by a cyclone, and a $1 \mu \mathrm{m}$ glassfibre filter. Upon removing the moisture, the exhaust gases were monitored by a battery of infrared $\left(\mathrm{SO}_{2}, \mathrm{CO}, \mathrm{CO}_{2}, \mathrm{NOx}\right.$ and $\left.\mathrm{N}_{2} \mathrm{O}\right)$ and paramagnetic $\left(\mathrm{O}_{2}\right)$ analysers.

The ignition tests in the entrained flow reactor were conducted at atmospheric pressure. Coal with a particle size fraction of 53-106 $\mu \mathrm{m}$ was fed in continuously at a rate of $0.5 \mathrm{~g}$ $\min ^{-1}$. The reactor was heated at $15^{\circ} \mathrm{C} \mathrm{min}^{-1}$ from 500 to $800{ }^{\circ} \mathrm{C}$. The experiments were conducted under stoichiometric conditions, in air, and 100\% excess oxygen. The gas flow rate employed was that necessary to ensure 2 seconds of residence time at $500{ }^{\circ} \mathrm{C}$ $\left(10 \mathrm{~cm}^{3} \mathrm{~min}^{-1}\right.$ at $25^{\circ} \mathrm{C}$ and $\left.1 \mathrm{~atm}\right)$.

Seven coals of varying rank and, therefore, different volatile matter content (which exerts a strong influence on ignition behaviour), were used: PE (Chile), IN (Indonesia), GU(Venezuela), LK (USA), CA, LD, HV (Spain). The main characteristics of these coals are given in Table 1.

For the purposes of comparison the coal ignition temperatures were also determined in a differential thermogravimetric analyser [7, 21]. In all the pyrolysis and combustion tests $5 \mathrm{mg}$ of sample was heated at $15^{\circ} \mathrm{C} \mathrm{min}{ }^{-1}$ from room temperature to $850{ }^{\circ} \mathrm{C}$. A gas flow rate of $50 \mathrm{~cm}^{3} \mathrm{~min}^{-1}$ was used; the inert gas for the pyrolysis experiments was argon whereas air was used as the reactive gas for the combustion tests. The experimental 
conditions from a previous work [22] were employed so as to ensure consistently reproducible results.

\section{Results and discussion}

The repeatability of the ignition tests in the entrained flow reactor was evaluated using coal PE. Figure 1 shows the variation in the concentration of different gases $\left(\mathrm{CO}, \mathrm{CO}_{2}\right.$, NO and $\mathrm{O}_{2}$ ) during three continuous experiments with coal PE in air; the gas evolution profiles for one of the high volatile coals (LK) are also included in this figure for comparison purposes. It can be seen that the repeatability of the temperature at which the ignition event occurs is very good, whichever gas is used for its determination. The results presented in the remaining part of this work correspond to the mean value of at least two experiments. At low temperatures, the production of $\mathrm{CO}$ increases, that of $\mathrm{CO}_{2}$ and NO shows a slight increase, and there is some $\mathrm{O}_{2}$ consumption due to the evolution of coal volatiles at low temperatures. However, the heat generation is not sufficient to sustain ignition and higher temperatures are necessary for ignition to occur. As can be seen in Figure 1, ignition is characterised by a rapid decrease in CO production, a significant $\mathrm{O}_{2}$ consumption, and an increase in the production of $\mathrm{CO}_{2}$ and $\mathrm{NO}$.

The definition of ignition temperature is somewhat arbitrary $[14,17]$. In this work the

criterion for determining the ignition temperature was based on the first derivative curves of the gases composition. The ignition temperature was taken as the temperature where the derivative curves, normalised with respect to the maximum derivative value, reached a value of $10 \%$. This is illustrated in Figure 2 for the evolution of $\mathrm{CO}_{2}$ corresponding to an ignition test for coal PE in air.

In order to study the effect of oxygen on ignition behaviour, a series of tests was conducted for PE at a fixed coal feed rate of $0.5 \mathrm{~g} \mathrm{~min}^{-1}$, the oxygen concentration 
varying from the stoichiometric value to $300 \%$ excess oxygen. The results obtained are depicted in Figure 3, which shows that increasing the excess oxygen leads to a clear decrease in the ignition temperature, due to the greater amount of oxygen available for the coal particles.

The ignition mechanism of the different rank coals was inferred from the evolution curves of the gases. The four high volatile bituminous coals (IN, GU, CA, LK) display a similar behaviour, i.e., two changes can be seen in their gas composition profiles. The first change corresponds to the combustion of the volatiles and the second to char combustion. This was confirmed by the constant increase in the $\mathrm{CO}_{2}$ produced after the ignition event. Thus, under the experimental conditions used in this work, the ignition of high volatile bituminous coals takes place via a homogeneous ignition mechanism, with the sequential ignition of volatiles and char.

A different behaviour was observed for the subbituminous coal, PE. The CO concentration decreased dramatically until nearly zero value, whereas that of $\mathrm{CO}_{2}$ increased drastically after ignition, maintaining thereafter a constant value. This behaviour is in accordance with a heterogeneous ignition mechanism, which involves the simultaneous ignition of volatiles and char. In the case of the subbituminous coal PE, this can be explained by the high reactivity of its char. Coal LD also exhibits a heterogeneous ignition mechanism, but in this case the ignition temperature is much higher than that of coal PE. Temperatures below $700{ }^{\circ} \mathrm{C}$ are not high enough for LD to ignite. However, after the ignition event $\left(709^{\circ} \mathrm{C}\right.$ in air), there is a steep increase in the $\mathrm{CO}_{2}$ evolution profile as a consequence of the relatively high char reactivity. The semianthracite, $\mathrm{HV}$, is clearly the least reactive coal in accordance with its rank and the more aromatic structure of higher rank coals. 
The influence of coal rank on ignition behaviour was also evaluated for the seven coals under stoichiometric, air, and $100 \%$ excess $\mathrm{O}_{2}$ conditions. The results summarised in Figure 4 verify the mutual dependence of ignition temperature and rank, since the values of Figure 4 indicate a decreasing trend of reactivity from PE (subbituminous) to HV (semianthracite). The ignition temperatures of the high volatile coals (IN, GU, CA and LK) remain practically constant. In all cases an increase in excess oxygen produces a decrease in the ignition temperature. It should also be taken into account that for coal PE the ignition tests conducted in air are equivalent to an oxygen excess of $300 \%$, while for the other coals the experiments in air correspond to an excess of oxygen in the 140$160 \%$ range.

The ignition temperatures evaluated from the TGA tests are also included in Figure 4 for purposes of comparison. In this work, the ignition temperatures determined by TGA (static method) are almost $300{ }^{\circ} \mathrm{C}$ lower than those evaluated in the entrained flow reactor (dynamic conditions), in accordance with the results summarised by Su et al. [2]. Although the operating conditions in the TGA and the EFR are very different, in this work a similar trend for the variation of ignition temperature with coal rank was obtained. In addition, the ignition mechanism of different rank coals analyzed on the basis of the TGA results of a previous work [10], coincides with the mechanism determined in this work in the entrained flow reactor. However, the mechanism and the temperature of ignition depend on the experimental technique, and other results on the ignition of coal blends have highlighted the differences in the ignition mechanism determined in the TGA and in the EFR [10, 23].

Furthermore, the morphological surface of the solid particles separated in the cyclone during the ignition tests in the entrained flow reactor was examined with a Zeiss DSM 942 scanning electron microscope. These observations provided additional confirmation 
of the mechanisms of ignition evaluated from the gas evolution profiles. The SEM micrographs shown in Figure 5 illustrate the events that take place before, during and after ignition for coals with a heterogeneous mechanism (exemplified by coal PE in Figures 5a to 5c), and for coals that present homogeneous mechanisms (represented by coal LK in Figures 5d to 5f). The surfaces of the particles of coal PE before ignition (Figure 5a), retain their original angular shape, and most of the particles do not show fissures. Microcracks, and also fissures, are more evident in Figure 5b which depicts the morphology of PE during ignition. In this case the original angular shape is retained but with the appearance of small pores. These features are more pronounced after ignition, once the combustion of coal PE takes place. This is clear from Figure 5c, which shows the irregularly reticulated exterior of the char particles from coal PE, with numerous openings.

In contrast, the behaviour displayed by the particles of the LK bituminous coal is markedly different to that of coals $\mathrm{PE}, \mathrm{HV}$ or $\mathrm{LD}$, which have a rather different structure and ignition mechanism. It can be observed in Figure 5d that the particles of the high volatile coal start to swell and to show signs of plasticity before ignition, and that externally they begin to show a rounded shape. The structure of coal LK during ignition is presented in Figure 5e; the particles which are of a cenospheric type, present a swollen structure and plastic features with some small degasification holes on their outer surface. The formation of these structures is typical of high volatile bituminous coals with plastic properties. However, contrary to the behaviour of coal PE, most of the particles of LK do not show signs of oxygen attack on the solid surface (Figure 5e). A SEM micrograph of the LK particles retrieved from the cyclone after ignition is shown in Figure 5f. It is clear that in the case of the high volatile bituminous coals there is a first stage, which involves devolatilisation followed by the ignition and combustion of 
the volatiles, and a second stage where the heterogeneous attack of oxygen on the char surface occurs (homogeneous ignition mechanism).

The method applied in this work for the assessment of coal ignition behaviour is much more rapid and cheaper than the tests in pilot-scale plants. Although the operating conditions are still different, they are certainly closer to industrial conditions than in the case of TGA. This methodology therefore will be used in order to evaluate the ignition behaviour and the interactive effects that might arise in the case of coal blends, for which the number of studies conducted in entrained flow reactors has been much smaller than in thermogravimetric systems.

\section{Conclusions}

The ignition behaviour of seven coals varied depending on their rank. The mechanism of ignition, evaluated in a laminar entrained flow reactor, changed from heterogeneous for subbituminous, low volatile bituminous and semianthracite coals, to homogeneous for high volatile bituminous coals. The results obtained in a TGA for the ignition mechanism and for the variation of the ignition temperature with coal rank were the same as those obtained in the EFR, although the more realistic conditions in the EFR make the results of this method more suitable for predicting the ignition behaviour of coal in industrial boilers. Observation by SEM of the morphological structure of the coal particles before, during and after the ignition event, provided additional confirmation of the ignition mechanism of the different rank coals.

\section{Acknowledgements}

Work carried out with the financial support of FONDECYT, Project 2010113 and MECESUP UCO0108 (Chile) which provided a mobility grant. 


\section{References}

[1] Essenhigh RH. Chemistry of coal utilisation, second supplementary volume 1981.

In: Elliot, MA, editor. London: Wiley; 1981. p. 1153.

[2] Su S, Pohl JH, Holcombe D, Hart JA. Prog Energ Combust Sci 2001; 27:75.

[3] Essenhigh RH, Misra MK, Shaw DW. Combust Flame 1989; 77:3.

[4] Annamalai K, Ryan W, Dhanapalan S. Prog Energ Combust Sci 1994; 20:487.

[5] Zhang DK, Wall TF. Fuel 1994; 73:1114.

[6] Herbig C, Jess A. Fuel 2002; 81:2387.

[7] Tognotti L, Malotti A, Petarca L, Zanelli S. Combust Sci Technol 1985; 44:15.

[8] Furimsky, E. Fuel Process Technol 1988; 19:203.

[9] Chen Y, Mori S, Pan WP. Thermochim Acta 1996; 275:149.

[10] Arenillas A, Rubiera F, Arias A, Pis JJ, Faúndez JM, Gordon AL, García XA. J Therm Anal Cal 2004; 76:603.

[11] Perkins, S, Zygourakis K. Ind Eng Chem Res 2004; 43:3085.

[12] Wall TF, Phong-Anant D, Gururajan VS, Wibberley LJ, Tate A, Lucas J. Combust Flame 1988; 72:111.

[13] Qiu J, Li F, Zeng H, Yao B, Ma Y. Combust Sci Technol 2000; 157:167.

[14] Fuertes AB, Hampartsoumian E, Williams A. Fuel 1993; 72:1287.

[15] Gupta RP, Gururajan VS, Lucas JA, Wall TF. Combust Flame 1990; 79:333.

[16] Tomeczek J, Wójcik J. 23rd symposium (international) on combustion. Pittsburg, PA: The Combustion Institute; 1990, p. 1177.

[17] Wall TF, Gupta RP, Gururajan VS, Zhang DK. Fuel 1991; 70:1011.

[18] Gomez CO, Vastola FJ. Fuel 1985; 64:558.

[19] Annamalai K, Ramalingan S. Combust Flame 1987; 70:307. 
[20] Stanmore BR, Choi YC, Gadiou R, Charon O, Gilot P. Combust Sci Technol 2000; 159:237.

[21] Chen Y, Mori S. Energy Fuels 1995; 9:71.

[22] Rubiera F, Arenillas A, Arias B, Pis JJ, Fuel Process Technol 2002; 77-78:111.

[23] Faúndez J, Rubiera F, García X, Arenillas A, Gordon AL, Pis JJ, 12th Int Conf on Coal Science, Cairns, Australia, 2003 


\section{List of Tables}

Table 1. Main characteristics of the coals used.

\section{List of Figures}

Figure 1. Gas emissions during ignition tests for coals PE and LK, in air.

Figure 2. Determination of the ignition temperature, during the entrained flow reactor tests, from the derivative of the $\mathrm{CO}_{2}$ concentration.

Figure 3. Variation of the ignition temperature with excess oxygen (30 $\mathrm{g} \mathrm{h}^{-1}$ coal PE feed rate).

Figure 4. Effect of coal rank on ignition temperature.

Figure 5. SEM micrographs of particles from coals PE and LK: a, d) before; b, e) during; c, f) after ignition. 
Table 1. Main characteristics of the coals used.

\begin{tabular}{|c|c|c|c|c|c|c|c|}
\hline Coal & $\mathrm{PE}$ & IN & GU & CA & LK & LD & $\mathrm{HV}$ \\
\hline \multicolumn{8}{|l|}{ Proximate Analysis } \\
\hline Ash (wt \%, db) & 20.7 & 1.7 & 4.3 & 8.5 & 6.2 & 4.7 & 8.2 \\
\hline V.M. (wt \%, daf) & 50.2 & 44.1 & 39.5 & 41.6 & 37.3 & 17.3 & 10.2 \\
\hline \multicolumn{8}{|l|}{ Ultimate Analysis (wt\%, daf) } \\
\hline $\mathrm{C}$ & 71.2 & 79.5 & 83.0 & 83.4 & 85.1 & 88.0 & 89.7 \\
\hline $\mathrm{H}$ & 5.3 & 5.5 & 5.2 & 5.5 & 5.0 & 3.8 & 3.3 \\
\hline $\mathrm{N}$ & 1.1 & 1.7 & 1.7 & 1.9 & 1.6 & 1.6 & 1.8 \\
\hline $\mathrm{S}$ & 0.6 & 0.5 & 0.8 & 1.7 & 0.8 & 3.5 & 2.0 \\
\hline O (by difference) & 21.8 & 12.8 & 9.3 & 7.5 & 7.5 & 3.1 & 3.2 \\
\hline Calorific Value $\left(\mathrm{MJ} \mathrm{kg}^{-1}, \mathrm{db}\right)$ & 22.72 & 31.96 & 32.83 & 31.51 & 33.31 & 33.30 & 32.39 \\
\hline \multicolumn{8}{|l|}{ Petrographic Analysis } \\
\hline Vitrinite (vol \%, mmf) & 88.9 & 89.8 & 78.4 & 89.3 & 66.7 & 78.8 & 94.7 \\
\hline Liptinite (vol \%, mmf) & 10.0 & 4.4 & 3.3 & 5.4 & 11.9 & 0.0 & 0.0 \\
\hline Inertinite (vol \%, mmf) & 1.1 & 5.8 & 18.3 & 5.3 & 21.4 & 21.2 & 5.3 \\
\hline Mean Reflectance (\%) & 0.38 & 0.57 & 0.67 & 0.74 & 0.87 & 1.87 & 2.24 \\
\hline Rank & sb & hvb & hvb & hvb & hvb & lvb & sa \\
\hline
\end{tabular}

db: dry basis; daf: dry ash free basis; mmf: mineral matter free basis; sb: subbituminous; hvb: high volatile bituminous; lvb: low volatile bituminous; sa: semianthracite. 

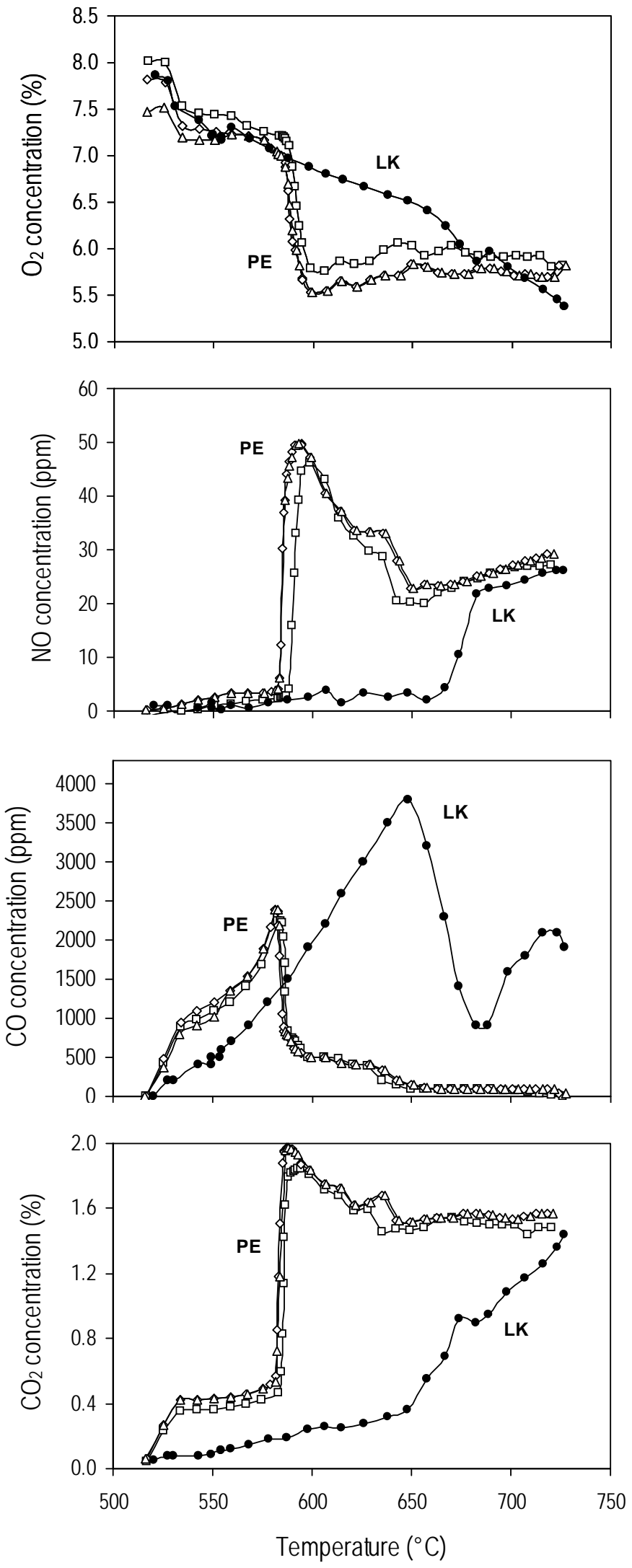

Figure 1.

Faúndez et al. 'Ignition behaviour ...' 


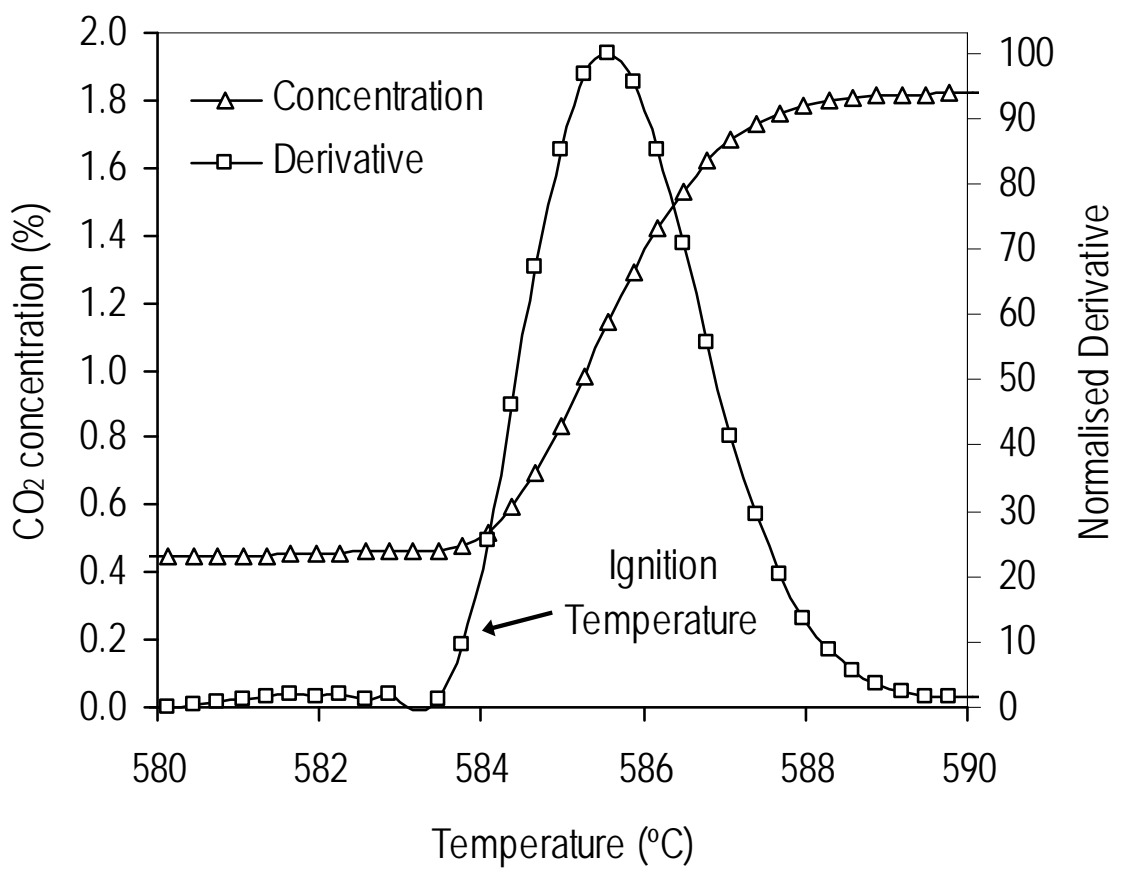

Figure 2.

Faúndez et al. 'Ignition behaviour ...' 


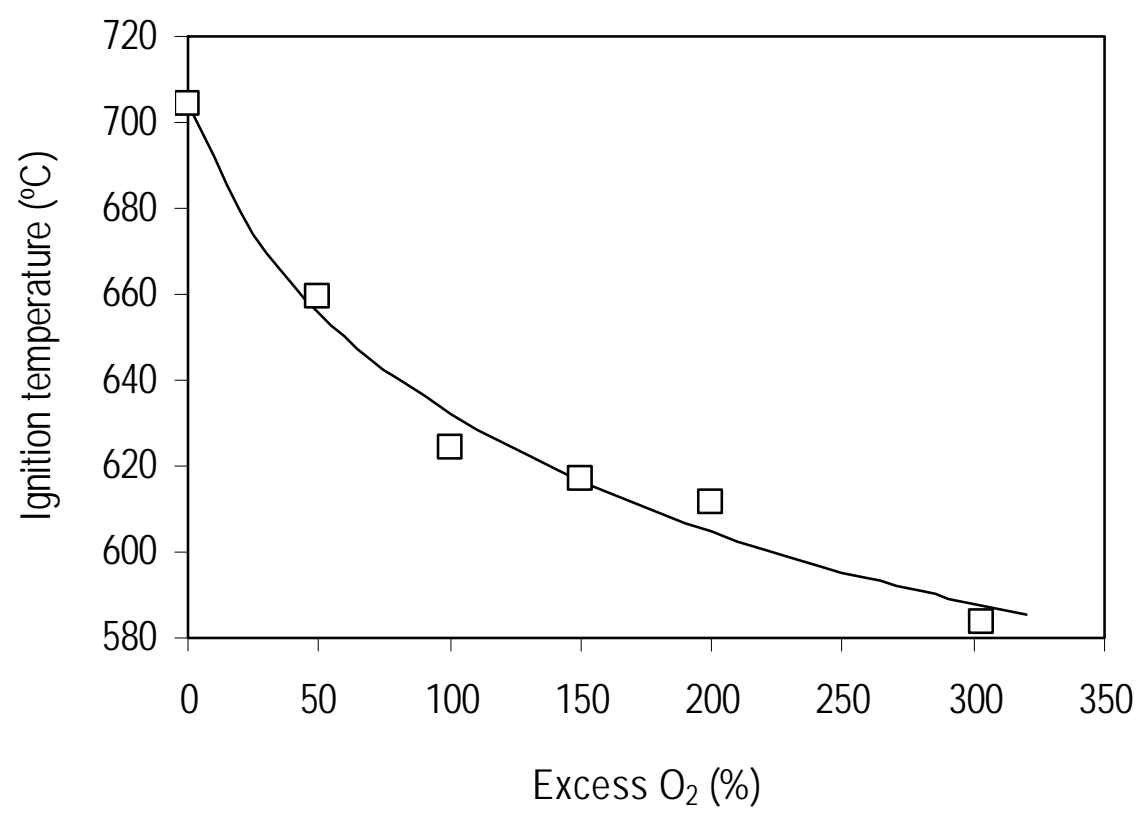

Figure 3.

Faúndez et al. 'Ignition behaviour ...' 


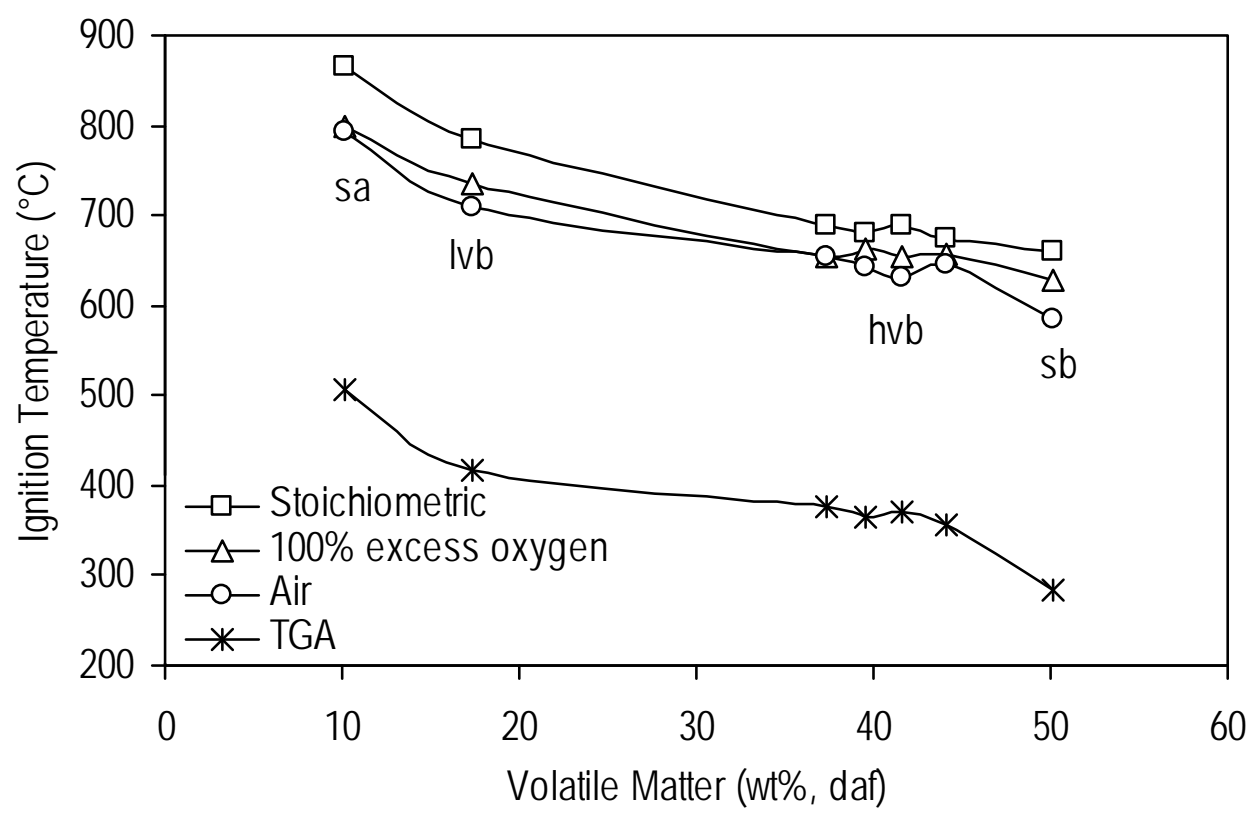

Figure 4.

Faúndez et al. 'Ignition behaviour ...' 

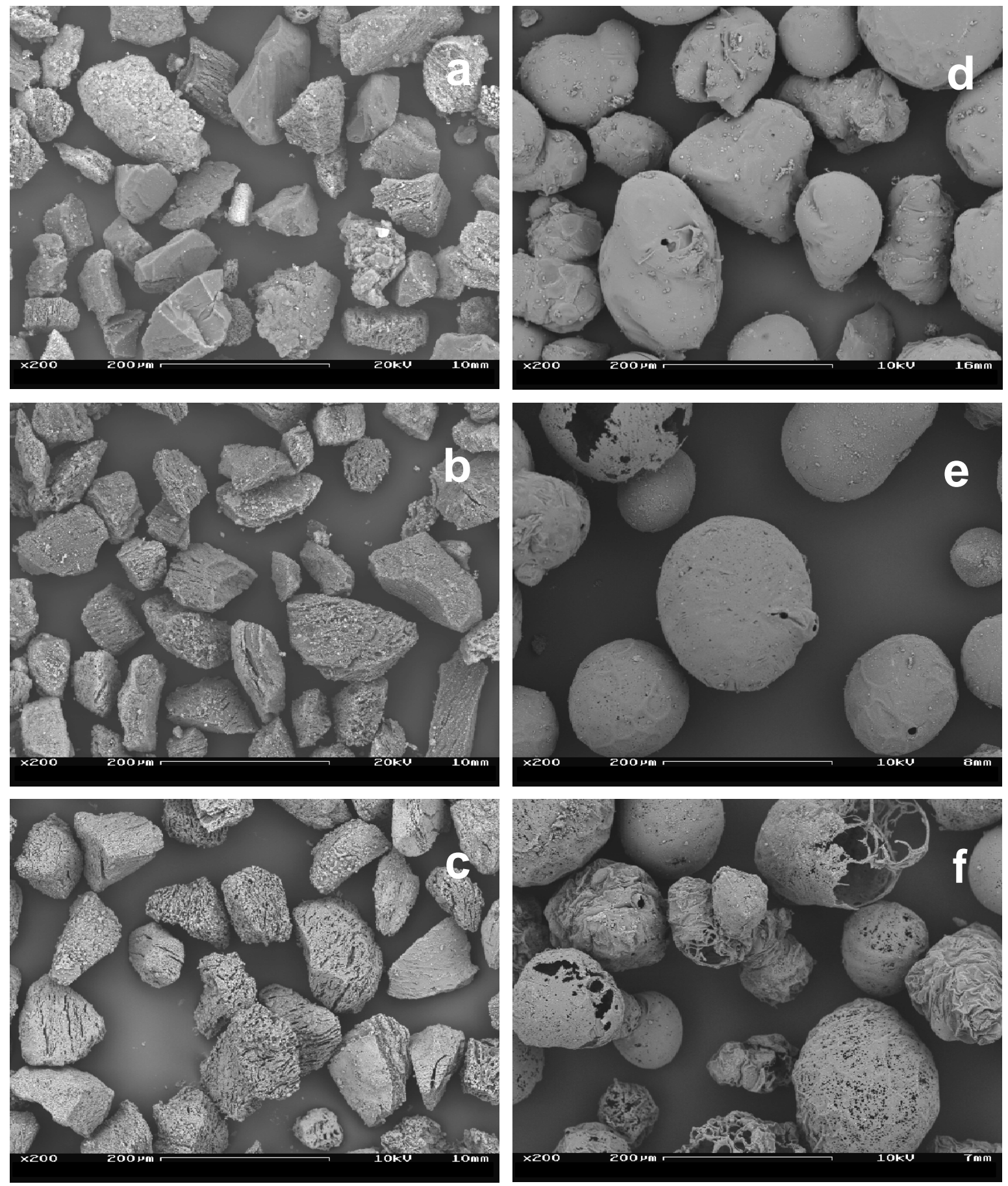

Figure 5.

Faúndez et al. 'Ignition behaviour ...' 